\title{
Relative importance of natural disturbances and habitat degradation on snail kite population dynamics
}

\author{
Julien Martin ${ }^{1,2,3, *}$, Wiley M. Kitchens ${ }^{1,2}$, Christopher E. Cattau ${ }^{1,2}$, Madan K. Oli ${ }^{2}$ \\ ${ }^{1}$ Florida Cooperative Fish and Wildlife Research Unit, Building 810, University of Florida, Gainesville, \\ Florida 32611-0485, USA \\ ${ }^{2}$ Department of Wildlife Ecology and Conservation, University of Florida, Gainesville, Florida 32611-0485, USA \\ ${ }^{3}$ Patuxent Wildlife Research Center, United States Geological Survey, 12100 Beech Forest Road, Laurel, \\ Maryland 20708, USA
}

\begin{abstract}
Natural disturbances and habitat degradation are major factors influencing the dynamics and persistence of many wildlife populations, yet few large-scale studies have explored the relative influence of these factors on the dynamics and persistence of animal populations. We used longterm demographic data and matrix population models to examine the potential effects of habitat degradation and natural disturbances on the dynamics of the endangered snail kite Rostrhamus sociabilis in Florida, USA. We found that estimates of stochastic population growth rate were low (0.90). Population growth rate $(\lambda)$ during the first half or our study period (1992 to 1998) was substantially greater than during the second half (1999 to 2005). These 2 periods were characterized by contrasting hydrological conditions. Although $\lambda$ was most sensitive to changes in adult survival, the analysis of life table response experiments revealed that a reduction in fertility of kites accounted for $>80 \%$ of the observed decline in population growth rate. We examined the possibility that the reduction in $\lambda$ was caused by (1) habitat degradation due to management, (2) an increase in frequency of moderate drying events in recent years, and (3) both habitat degradation and an increase in frequency of moderate drying events. Our results suggest that both factors could potentially contribute to a large decrease in population growth rate. Our study highlights the importance of simultaneously considering short- and long-term effects of disturbances when modeling population dynamics. Indeed, focusing exclusively on one type of effect may be misleading to both our understanding of the ecological dynamics of the system and to management. The relevance of our results to management is heightened because the snail kite has been selected as a key performance measure of one of the most ambitious ecosystem restoration projects ever undertaken.
\end{abstract}

KEY WORDS: Matrix population models $\cdot$ Life table response experiment $\cdot$ Everglades restoration · Fecundity $\cdot$ Catastrophes

\section{INTRODUCTION}

Natural disturbances are environmental events that generally induce temporary changes in the system state (Reeves et al. 1995). In contrast, habitat degradation typically results from human activities and often leads to more permanent changes in the system state
(Reeves et al. 1995). Natural disturbances are often perceived as 'catastrophes' (e.g. floods, droughts) that impose large numerical responses on wild populations (Casagrandi \& Gatto 2002). However, natural disturbances may also play a role in organizing ecosystems (DeAngelis \& White 1994). In the long term, natural disturbances may be crucial to the persistence of wild 
populations (DeAngelis \& White 1994). Because most wildlife studies are conducted in the short term and at relatively small spatial scales, most studies investigating the effects of natural disturbances on natural populations have focused on the negative effects of disturbances (White \& Pickett 1985). However, suppressing natural disturbances can actually result in the degradation of natural habitats with long-term consequences for populations inhabiting these systems (Reeves et al. 1995). Better understanding the relative importance of natural disturbances and habitat degradation on populations, both in the short and long terms, is an important challenge to uncover the ecological dynamics of many natural systems.

We examined several hypotheses related to the effect of natural disturbances and habitat degradations on population dynamics of the federally endangered snail kite Rostrhamus sociabilis. The snail kite is a wetland specialist whose diet consists almost exclusively of freshwater snails (Beissinger 1995). Vital rates of snail kites are finely tuned to the hydrology of its habitat. Drying events reduce availability of snails to kites and, therefore, can dramatically increase mortality (Takekawa \& Beissinger 1989, Martin et al. 2006, Martin et al. 2007a). The impact of drying events on kites depends on the intensity, spatial extent and duration of these disturbances (Bennetts \& Kitchens 2000, Mooij et al. 2007). Drying events often occur naturally, but in some instances can be induced by management (e.g. managed drawdowns). As pointed out by several authors, droughts are natural disturbances that are an organizing force of Florida ecosystems and suppressing them may cause habitat conversion (Bennetts et al. 1998, Kitchens et al. 2002, Mooij et al. 2007). In addition, prolonged hydroperiods and excessive flooding intensity and frequency may shift the vegetation structure toward communities less suitable for foraging and nesting activities of snail kites (Kitchens et al. 2002, Darby et al. 2005, Zweig \& Kitchens 2007). This contrasts with the fact that occasional flooding events are part of the system and may even benefit kites in the short term (Bennetts et al. 2002). During the period 1993 to 2005, most primary kite habitats in Florida experienced a high frequency of flooding events and unusually prolonged hydroperiods during the fall, and a single extensive drought was reported in 2001 (Smith et al. 2003, Martin 2007). The increase in flooding frequency resulted from an increase in precipitation as well as from the regulation of control structures, particularly in Everglades Water Conservation Area 3A (WCA3A) (SFWMD 2007a). In this study we consider habitat conversion resulting from increased flooding frequency as a type of habitat degradation. Several authors have argued that these changes in hydropatterns may have degraded kites' habitat (Kitchens et al.
2002). Martin et al. (2007b) noted that the number of juveniles appeared to decrease dramatically after 1998. The 2001 drought had a large effect on kite survival and the population decreased substantially after 2001; the kite population has not recovered since (Martin et al. 2007b). Adult survival does not appear to have been reduced substantially, except during the drought that occurred in 2001, but juvenile survival appears to have decreased since 1999 (Martin et al. 2006). Based on these observations, we defined 2 periods: a pre-1998 period (1992 to 1998) and a post-1998 period (1999 to 2005). The pre-1998 period reflected a pre-decline environment (i.e. before the number of young produced decreased, see Martin et al. 2007b). These 2 periods are equivalent in time lengths but are also characterized by contrasting hydrological conditions (see 'Hydrological conditions' in 'Materials and methods'). In addition, Bennetts et al. (1998) hypothesized that in the absence of a drying event for 5 to $6 \mathrm{yr}$ the quality of snail kite habitats would start to erode (they referred to this erosion of habitat quality as 'habitat degradation'). Based on this hypothesis we would expect habitat degradation to have begun to occur in 1998 because there was no drying event between 1993 and 1998 (see 'Hydrological conditions' in 'Materials and methods'). Kitchens et al. (2002) also hypothesized that it could take a decade or more for the habitat to recover from this type of habitat degradation.

Therefore, based on past research on kites (e.g. Bennetts et al. 1998, Kitchens et al. 2002, Darby et al. 2005, Mooij et al. 2007, Martin 2007, Zweig \& Kitchens 2007), we considered 3 primary hypotheses to explain the lack of recovery of the kite population after the 2001 drought. First, we considered the habitat degradation hypothesis, which assumes that an increase in frequency of flooding events (during August to January, hereafter referred to as the fall; this period includes some of the months during which water levels are at their highest) has led to a deterioration of foraging and nesting habitats of kites (Hypothesis 1). As explained earlier, habitat degradation could also have resulted from the absence of drying events between 1993 and 1998 (and no drought occurred until 2001). Second, we considered the hypothesis that an increase in moderate drying events during March to June (hereafter referred to as the spring-summer; this period includes some of the months during which water levels are at their lowest) is limiting recovery (Hypothesis 2). Indeed, Martin (2007) found that after 1998 there was an increase in moderate drying events in WCA3A during the spring-summer (which includes the peak of the breeding season). As explained in 'Hydrological conditions,' moderate drying events are more moderate disturbances than droughts. Finally, we considered Hypothesis 3, which assumes that both 
habitat degradation and an increase in moderate drying events are limiting population growth rate of kites.

It is important to recognize that analyses associated with the examination of Hypotheses 1,2 and 3 are exploratory. The goal of our exploratory analyses was not to demonstrate the effect of specific factors (e.g. habitat degradation) on population growth rate. Instead, our objective was to measure the potential impact of selected factors in the context of each of the 3 hypotheses. For example, in the context of Hypothesis 1 our question was, what would be the magnitude of the effect of habitat degradation on population growth rate of kites if, in fact, Hypothesis 1 was true? We applied the same reasoning for Hypotheses 2 and 3.

We selected these 3 hypotheses because they are the most relevant to current management of kite habitats and are also among the hypotheses best supported by the existing literature (e.g. Kitchens et al. 2002, Darby et al. 2005, Martin 2007, Mooij et al. 2007, Zweig \& Kitchens 2007).

\section{Objectives}

Beissinger (1995) used matrix population models to examine the viability of kites in relation to drought frequency. In this paper we used a similar matrix pop- ulation approach to address 6 primary objectives. Objective 1 was to estimate population growth rate of kites under current conditions. Objective 2 was to determine the key vital rates that govern the population growth of the kite population (based on sensitivity and elasticity analyses). Objective 3 was to estimate how differences in vital rates between the preand post-1998 environments have contributed to changes in population growth rates (we used 1-way Life Table Response Experiment [LTRE, Caswell 2001] to meet this objective). Objective 4 was to examine Hypothesis 1 and to evaluate the relative importance of an increase in drought frequency as opposed to the before versus after 1998 effect on population growth rate (e.g. due to habitat conversion under Hypothesis 1). In order to address Objective 4 we estimated stochastic population growth rates for pre- and post-1998 environment and varied the frequency of droughts. Objective 5 was to examine a hypothesis that assumed the primary factor responsible for lack of population recovery was related to an increase in moderate drying events and not to habitat degradation (Hypothesis 2). Objective 6 was to examine a hypothesis that assumed that both an increase in moderate drying events frequency and habitat conversion were responsible for lack of recovery of kites (Hypothesis 3, see Table 1 for a summary of all objectives, hypotheses and predictions).

Table 1. Description of the objectives, hypotheses, predictions and analyses presented in the text. See Table 2 for a list of abbreviations and symbols

\begin{tabular}{|c|c|}
\hline Objectives & Description \\
\hline $\begin{array}{l}\text { Objective } 1 \\
\text { Analyses }\end{array}$ & $\begin{array}{l}\text { Measure population growth rate of snail kites under current conditions } \\
\text { Estimation of stochastic population growth rate }\left(\lambda_{s}\right) \text {, results presented in text }\end{array}$ \\
\hline $\begin{array}{l}\text { Objective } 2 \\
\text { Analyses }\end{array}$ & $\begin{array}{l}\text { Determine key vital rates that govern the population dynamics of kites } \\
\text { Sensitivity and elasticity analyses, results presented in Fig. } 1\end{array}$ \\
\hline $\begin{array}{l}\text { Objective } 3 \\
\text { Analyses }\end{array}$ & $\begin{array}{l}\text { Determine how changes in vital rates before and after } 1998 \text { have contributed to changes in } \lambda_{1} \\
\text { Life Table Response Experiment (LTRE), based on matrices } \mathbf{A}_{\text {bef }} \text { and } \mathbf{A}_{\text {aft }} \text { results presented in Fig. } 2\end{array}$ \\
\hline $\begin{array}{l}\text { Objective } 4 \\
\text { Hypothesis } 1 \\
\text { Prediction } 1 \\
\text { Analyses }\end{array}$ & $\begin{array}{l}\text { Exploration of Hypothesis } 1 \\
\text { Habitat conversion reduced } \lambda_{s} \text { after } 1998 \\
\lambda_{s} \text { under Condition } 1>\lambda_{s} \text { under Condition } 3 \text {; and } \lambda_{s} \text { under Condition } 2>\lambda_{s} \text { under Condition } 4 \\
\text { Estimation of } \lambda_{s} \text { before (based on matrix } \mathbf{A}_{b e f} \text { ) and after } 1998 \text { (based on matrix } \mathbf{A}_{a f t} \text { ), with } 2 \text { levels of } \\
\text { drought frequencies (frequency of } 0.25 \text { and 0.11), results presented in Fig. } 3\end{array}$ \\
\hline $\begin{array}{l}\text { Objective } 5 \\
\text { Hypothesis } 2 \\
\text { Prediction } 2 \\
\text { Analyses }\end{array}$ & $\begin{array}{l}\text { Exploration of Hypothesis } 2 \\
\text { Increase in moderate drying events reduced } \lambda_{s} \text { after } 1998 \\
\lambda_{s} \text { under Condition } 5>\lambda_{\mathrm{s}} \text { under Condition } 6 \\
\text { Estimation of } \lambda_{s} \text { based on matrices } \mathbf{A}_{\text {wet } 1}, \mathbf{A}_{\text {mod }} \text { and } \mathbf{A}_{d r o} \text {, with frequency observed before } 1998 \text { (LFMD) } \\
\text { and after } 1998 \text { (HFMD), results presented in Fig. } 4\end{array}$ \\
\hline $\begin{array}{l}\text { Objective } 6 \\
\text { Hypothesis } 3 \\
\text { Prediction 3a } \\
\text { Prediction 3b } \\
\text { Analyses }\end{array}$ & $\begin{array}{l}\text { Exploration of Hypothesis } 3 \\
\text { Both an increase in moderate drying events and habitat conversion reduced } \lambda_{\mathrm{s}} \text { after } 1998 \\
\lambda_{s} \text { under Condition } 7>\lambda_{\mathrm{s}} \text { under Condition } 8 ; \text { and } \lambda_{\mathrm{s}} \text { under Condition } 9>\lambda_{\mathrm{s}} \text { under Condition } 10 \\
\lambda_{s} \text { under Condition } 7>\lambda_{s} \text { under Condition } 9 ; \text { and } \lambda_{s} \text { under Condition } 8>\lambda_{\mathrm{s}} \text { under Condition } 10 \\
\text { Estimation of } \lambda_{s} \text { based on matrices } \mathbf{A}_{w e t 2} \mathbf{A}_{m o d} \text { and } \mathbf{A}_{d r o} \text { to simulate conditions before } 1998 \text { and matrices, } \\
\mathbf{A}_{w e t 3}, \mathbf{A}_{m o d} \text { and } \mathbf{A}_{\text {dro }} \text { to simulate conditions after } 1998 ; \text { frequency of each matrix was based on frequen- } \\
\text { cies observed before } 1998 \text { (LFMD) and after } 1998 \text { (HFMD), results presented in Fig. } 5\end{array}$ \\
\hline
\end{tabular}




\section{MATERIALS AND METHODS}

Study area. The snail kite population in Florida, USA is believed to be geographically isolated. Kites in Florida have been monitored by capture-mark-recapture since 1992 (Martin et al. 2006). Multiple, consecutive surveys of kites from airboats have been conducted during the peak of the breeding season throughout the species' Florida range. The sampled areas include the Kissimmee-Chain of Lakes, the Water Conservation Areas (1,2A, 2B, 3B and 3A), Everglades National Park, Big Cypress National Preserve, Saint Johns Marsh, Lake Okeechobee, and Loxahatchee (see Martin et al. 2006 for a detailed map).

Hydrological conditions. Martin (2007, p 165-168) performed an agglomerative hierarchical clustering analysis in order to establish 3 groups of years characterized by contrasted hydrological conditions: wet years (1993-1998, 2003 and 2005), moderately dry years (1999-2000, 2002 and 2004), and drought years (1992 and 2001). Droughts were characterized by the greatest intensity (i.e. lowest water levels during the dry season), the longest duration and the greatest spatial extent (i.e. proportion of wetlands affected by dry conditions). Therefore the pre-1998 period was dominated by wet years, whereas the post-1998 period was dominated by dry years.

All but 1 hydrological variable (spatial extent) was measured in Everglades WCA3A. We focused on WCA3A because it has been identified as the single most important wetland unit currently occupied by kites (Mooij et al. 2002); moreover, hydrological conditions in WCA3A are highly correlated with conditions in all the WCAs, Everglades National Park and Lake Okeechobee, which by far constitute the largest extent of wetlands occupied by kites (Martin 2007).

Estimates of vital demographic rates. Survival rates. Estimates of age-specific annual survival probabilities for the period 1997 to 2004 were obtained from Martin (2007, p 138). This author used Cormack-Jolly-Seber models to estimate survival implemented in Program MARK (White \& Burnham 1999). Note that herein we refer to survival probabilities as $P_{a}$ (for adults [ $\left.\geq 2 \mathrm{yr}\right]$ ), $P_{s}$ (for subadults [1 to $2 \mathrm{yr}$ ]); and $P_{j}$ (for juveniles [fledging to $1 \mathrm{yr}]) . P_{a^{\prime}} P_{s^{\prime}}$ and $P_{j}$ for year $t$ (e.g. 2000), correspond to survival probabilities for the interval $t$ to $t+1$ (e.g. 2000 to 2001).

Fecundity rates. In order to construct population projection models we need to estimate fecundity rates, which in our case is the number of young females produced per reproductive female (Caswell 2001, Morris \& Doak 2002). Estimates of fecundity of adults $\left(m_{a}\right)$ and fecundity of subadults $\left(m_{s}\right)$ were obtained as follows:

$$
\hat{m}_{a}(t)=\frac{\hat{N}_{j}(t)}{\hat{N}_{a}(t)+\frac{\hat{N}_{s}(t)}{\hat{q}(t)}}
$$

where $\hat{N}_{a}(t)$ is the estimated number of adult females and $\hat{N}_{j}(t)$ the estimated number of juvenile females in the population (see Appendix 1 for details on how to derive Eq. 1). $\hat{q}(t)$ is the estimated ratio of fecundity rates:

$$
\hat{q}(t)=\frac{\hat{m}_{a}}{\hat{m}_{s}}, \text { hence, } \hat{m}_{s}=\frac{\hat{m}_{a}}{\hat{q}(t)}
$$

(see also Appendix 2).

In 2004 and 2005 we directly estimated the number of juveniles in the population (see Martin et al. 2007b). The number of juvenile females was obtained by dividing these super-population estimates for juveniles by 2 because we assumed a sex ratio of 50:50. For the period 1992 to 2003 we did not have estimates of the number of juveniles, but counts were available. For these years, $\hat{N}_{j}(t)$ was estimated as:

$$
\hat{N}_{j}(t)=\frac{C_{j}(t)}{\hat{\beta}(t)}
$$

where $C_{\mathrm{j}}(t)$ is the number of juvenile females counted at time $t$ and $\hat{\beta}(t)$ is the fraction of juveniles counted from the overall population of juveniles at time $t$ (hereafter referred to as detection probability of juveniles [see Martin et al. 2007b]). The procedure leading to estimate $\hat{\beta}(t)$ is described in Appendix 3. The number of adults at time $t$ was estimated as:

$$
\hat{N}_{a}(t)=\hat{N}_{S U P}(t)-\hat{N}_{s}(t)
$$

where $\hat{N}_{S U P}(t)$ is the estimate of super-population size of females at time $t$ (estimates of $\hat{N}_{S U P}(t)$ were computed by dividing superpopulation size estimates by 2 , assuming a 50:50 sex ratio; estimates of super-population size were obtained from Martin 2007). $\hat{N}_{s}(t)$ in Eq. (3) corresponds to the number of subadult females at time $t$, which was estimated as:

$$
\hat{N}_{s}(t)=\hat{N}_{j}(t-1) \times \hat{P}_{j}(t-1)
$$

We computed $\hat{q}(t)$ (see Eq. 1) based on estimates obtained from Bennetts (1998). We obtained $\hat{q}(t)=4.2$ (see Appendix 2). Varying $\hat{q}(t)$ from 4 to 8.8 had little effect on population growth rates and other relevant measures. Note that $m_{a}$ and $m_{s}$ for year $t$ correspond to fecundity at time $t$. Estimates of fecundity were available between 1997 and 2005 .

Detection probability for juveniles. Estimates of detection probability for juveniles $(\hat{\beta}(t))$ were needed to compute fecundity rates. We repeated all the analyses $\left(\lambda_{s !}\right.$ sensitivity, elasticity, LTRE) assuming 3 levels of $\hat{\beta}(t)$ to evaluate the robustness of our results (see Appendix 3 for details on how $\hat{\beta}(t)$ was derived). Firstly, we assumed that $\hat{\beta}(t)$ was constant over time and was equal to 0.16 (this estimate was the lowest of our empirical estimates and probably underestimated the 'true' detection probability for most years; this resulted in the most optimistic scenarios, see Appendix 3). Secondly, we 
assumed that $\hat{\beta}(\mathrm{t})$ was constant over time but was equal to 0.70 (this estimate probably greatly overestimated the 'true' detection probability, see Appendix 3). Thirdly, we assumed that $\hat{\beta}(\mathrm{t})$ varied from 0.16 to 0.35 , this third level of detection probability was assumed to be the most reasonable (Appendix 3).

Construction and analysis of matrix population models. We constructed and analyzed matrix population models with all 3 life-history stage classes and, as did Beissinger (1995), we assumed a 50:50 sex ratio. We also assumed a pre-breeding census and considered only the female part of the population (Caswell 2001). Juveniles survive the first year of their lives with probability $P_{j}$. Subadult and adult females survive with $P_{s}$ and $P_{a}$, respectively. Adults remain in the same stage throughout their lives and survive each year with survival probability $P_{a}$. Fertility rates for adult $\left(F_{a}\right)$ and subadult $\left(F_{s}\right)$ kites were estimated using the prebreeding census formulation of Caswell (2001):

$$
F_{a}=P_{j} \times m_{a}
$$

and

$$
F_{s}=P_{j} \times m_{s}
$$

Using these parameters, the pre-breeding census population projection matrix was:

$$
\mathbf{A}=\left[\begin{array}{ll}
F_{s} & F_{a} \\
P_{s} & P_{a}
\end{array}\right]
$$

See Table 2 for a complete list of symbols.

Stochastic population growth rate for 1997 to 2004 (Objective 1). Using estimates of demographic parameters for each year from 1997 through 2004, we constructed 8 population projection matrices (i.e. 1 matrix $\mathrm{yr}^{-1}$ ). We assumed identically and independently distributed (iid) environment, and that each year occurred with equal probability, and estimated stochastic population growth rate $\left(\lambda_{\mathrm{s}}\right)$ as (Caswell 2001, Morris \& Doak 2002):

$$
\widehat{\log \lambda_{s}}=\frac{1}{T} \sum_{t=0}^{T-1} r_{t}
$$

Table 2. List of symbols used in the text, tables and figures

\begin{tabular}{|ll|}
\hline \multicolumn{2}{|c|}{ Symbols } \\
\hline$\lambda_{s}$ & Definitions \\
$P_{i}$ & Stochastic population growth \\
$m_{i}$ & Fecundity for stage class $i$ (subadults $[s]$ and adults $[a])$ \\
$F_{i}$ & Fertility for stage class $i$ (subadults $[s]$ and adults $[a])$ \\
$\hat{\beta}(t)$ & Detection probability of juveniles. \\
$\mathbf{A}_{\text {bef }}$ & Matrix based on $m_{i}(1997-1998)$ and $P_{i}(1992-1998)$ \\
$\mathbf{A}_{\text {aft }}$ & Matrix based on $m_{i}(1999,2000,2002-2005)$ and $P_{i}(1999,2002-2004)$ \\
$\mathbf{A}_{\text {dro }}$ & Matrix based on $m_{i}(2001), P_{a}(2001), P_{s}(2001)$ and $P_{j}(2000-2001)$ \\
$\mathbf{A}_{\text {mod }}$ & Matrix based on $m_{i}(1999,2000,2002,2004)$ and $P_{i}(1999,2000,2002,2004)$ \\
$\mathbf{A}_{\text {wet1 }}$ & Matrix based on $m_{i}(1997,1998,2003,2005)$ and $P_{i}(1993-1998,2003)$ \\
$\mathbf{A}_{\text {wet2 }}$ & Matrix based on $m_{i}(1997,1998)$ and $P_{i}(1993-1998)$ \\
$\mathbf{A}_{\text {wet3 }}$ & Matrix based on $m_{i}(2003,2005)$ and $P_{i}(2003)$ \\
\hline
\end{tabular}

where $T$ is the simulation time (set to $10000 \mathrm{yr}$ ), and:

$$
r_{t}=\log \frac{(N(t+1))}{(N(t))}
$$

where $N(t)$ is the projected population size at time $t$. We computed an approximate $95 \% \mathrm{CI}$ as:

$$
\widehat{\log \lambda_{s}} \pm 1.96 \sqrt{\frac{V(r)}{T}}
$$

where $V(r)$ is the variance of $r_{t}$. The initial population vector was based on estimates from 2005 (Martin et al. $2007 b$ ). For this simulation we used data from 1997 to 2004 (instead of 1997 to 2005), which allowed us to relax assumptions about probability distribution of vital rates and correlation among vital rates.

Sensitivity and elasticity analysis (Objective 2). We followed procedures described by Caswell (2001) to compute sensitivities and elasticities of population growth rate to changes in vital rates $F_{s}, F_{a}, P_{s}$ and $P_{a}$. Sensitivity measures how absolute changes in individual vital rates influence population growth rate (Caswell 2001). Elasticity measures the proportional change in population growth rate resulting from a proportional change in individual vital rates (Morris \& Doak 2002, Caswell 2001).

In order to obtain sensitivity metrics of $m_{s}, m_{a}$, and $P_{j}$ we computed lower levels sensitivity and elasticity (Caswell 2001).

Analysis of Life Table Response Experiment (LTRE, Objective 3). We applied a deterministic, fixed design 1-way LTRE, as described by Caswell (2001), to assess how differences in vital rates before and after 1998 contributed to changes in deterministic population growth rate $\left(\lambda_{1}\right.$, which corresponds to the dominant eigenvalue of a projection matrix [Caswell 2001]). We constructed a population projection matrix using demographic data collected during 1993 to $1998\left(\mathbf{A}_{b e f}\right)$. Likewise, we constructed a population projection matrix using data collected after $1998\left(\mathbf{A}_{a f t}\right)$. The finite population growth rates were then estimated as the dominant eigenvalues of the respective population projection matrices (Caswell 2001). The difference in the growth rate quantified the change in population growth rate following 1998 . We then decomposed the observed change in population growth as due to changes in demographic parameter using the fixedeffect, 1-way LTRE analysis (Caswell 2001, Oli et al. 2001, Bruna \& Oli 2005) as:

$$
\left.\Delta \lambda \approx \sum_{i j} \Delta a_{i j} \frac{\partial \lambda}{\partial a_{i j}}\right|_{\left(\frac{\mathrm{A}_{a f t}-\mathrm{A}_{b e f}}{2}\right)}
$$

where $\Delta \lambda=\lambda_{\text {bef }}-\lambda_{\text {aft }}$ is the ob- 
served reduction in population growth rate after 1998, $\Delta a_{i j}=a_{a f t}-a_{b e f}$ is the observed change in a vital rate, and the term $\Delta a_{i j} \frac{\partial \lambda}{\partial a_{i j}}$ quantifies the contribution of $\Delta a$ to $\Delta \lambda$. The sensitivity $\partial \lambda / \partial a_{i j}$ was evaluated at the midpoint of the before and after value of a vital rate (Caswell 2001). Survival rates included in $\mathbf{A}_{\text {bef }}$ were computed as the average annual survival for the interval 1993 to 1998, excluding estimates for 1992 identified by Martin (2007, p 168) as a drought year. Fertilities were computed as the product of the average juvenile survival rates (for 1993 to 1998) and the average fecundity for the interval 1997 to 1998 . Survival and fertility rates for $\mathbf{A}_{\text {aft }}$ included estimates from 1999 to 2005, excluding estimates of survival and fertilities affected by the 2001 drought (see Appendix 4). We also conducted an LTRE analysis in which we decomposed fertilities $(F)$ into their lower level components (i.e. $m_{s}$ and $P_{j}$ for $F_{s} ; m_{a}$, and $P_{j}$ for $F_{a}$ ).

Stochastic population growth rate to examine Hypotheses 1, 2 and 3. For these simulations we used Eq. (7). However, because the focus of these analyses was to explore hypotheses (rather than provide an accurate estimate of $\lambda_{s}$ under the current conditions) we used most of the data available in our data set for the period 1992 to 2005. This implies that for this set of analyses we had to make additional assumptions about the probability distribution of vital rates and the correlation among vital rates (Morris \& Doak 2002).

$T$ was set to 10000 time steps (see Eq. 7). The initial population size and population structure were set based on estimates from 2005 (Martin et al. 2007b). The simulations assumed iid sequences of $T$ time steps and we used a maximum of 3 environmental states. The frequency of occurrence of each state varied depending on the scenario being simulated. Each environmental state was associated with 1000 matrices, which accounted for the variance of each vital rate, as well as the within-year correlation among vital rates. At each time step the model checked the environmental state and drew a projection matrix at random (from the 1000 matrices associated with the corresponding state) and estimated $\mathbf{n}(t+1)$ (the population vector at time $t+1$ whose entries $n_{i}[t+1]$ contained the number of individuals in each stage class at time $t+1$ ) by multiplying the projection matrix by the population vector $\mathbf{n}(t)$ (Caswell 2001). $N(t)$ and $N(t+1)$ (the total number of females at time $t$ and $t+1$, respectively, see Eq. 7) were obtained by summing the number of individuals in each age class from population vectors $\mathbf{n}(t)$ and $\mathbf{n}(t+1)$.

For all the stochastic analyses, we incorporated the variance associated with each vital rate (which included both process and sampling variance), as well as the within-year correlation among vital rates using the approach described by Morris \& Doak (2002, p 284-285). The correlation matrix was computed based on fecundity and survival rates for the period 1997 to 2004. As suggested by Morris \& Doak (2002), we used the stretched-beta distribution to simulate random variation in fecundity rates, whereas we used the beta distribution to simulate random variation in survival rates. The stretched-beta is a rescaled beta distribution that includes a minimum and maximum value to fit intervals that makes biological sense. Because it is bounded by biologically meaningful limits the stretched-beta distribution allow more realistic simulations of fertility and fecundity rates than, for instance, the commonly used lognormal distribution (Morris \& Doak 2002, Koons et al. 2006). The variance for each parameter (e.g. survival and fecundity) included both sampling and process variance. We found little difference between total variances and process variances for most vital rates under consideration; therefore we expect our estimates of $\lambda_{s}$ to be fairly robust to the inclusion or exclusion of sampling variance in our analyses. In instances where only 1 estimate was available (e.g. drought year of 2001), we used the sampling variance. Variances for derived parameters were computed using the delta method (Williams et al. 2002). We estimated $\lambda_{\mathrm{s}}$ for 10 sets of environmental conditions (denoted by Condition $x_{1}$ with $x=1$ through 10 , see below).

Examination of Hypothesis 1: habitat conversion caused a reduction of $\lambda_{s}$ after 1998 (Objective 4). Hypothesis 1 assumes that habitat degradation has caused a reduction in $\lambda_{\mathrm{s}}$ after 1998 .

- Conditions 1 and 2: we computed $\lambda_{\mathrm{s}}$ for the environmental state that corresponded to the period before 1998. This simulation was based on 2 matrices. (1) One matrix summarized the conditions before 1998 (i.e. means and variances were obtained for the period 1993 to 1998). (2) One matrix summarized the drought conditions $\mathbf{A}_{\text {dro }}$ (see Table 2 and Appendix 4). We estimated 2 values of $\lambda_{s}$ : one assuming a drought frequency of 0.11 (i.e. drought occurred on average every 9 yr: Condition 1) and another assuming a drought frequency of 0.25 (i.e. 1 drought every 4 yr: Condition 2).

- Condition 3: same as Condition 1, but for the environmental state corresponding to the period after 1998.

- Condition 4: same as Condition 2, but for the environmental state corresponding to the period after 1998.

Under Hypothesis 1 we make Prediction 1: $\lambda_{s}$ under Condition $1>\lambda_{s}$ under Condition 3 ; and $\lambda_{s}$ under Condition $2>\lambda_{s}$ under Condition 4 .

Hypothesis 2: increase in drying event frequency reduced $\lambda_{s}$ after 1998 (Objective 5). Hypothesis 2 assumes that an increase in moderate drying events frequency has caused a reduction in $\lambda_{\mathrm{s}}$ after 1998. In 
the section 'Hydrological conditions' we explained that the frequency of moderate drying events was greater after 1998 than before 1998.

- Condition 5: we computed $\lambda_{\mathrm{s}}$ by simulating an environment with 3 environmental states: $\mathbf{A}_{\text {wet1 }}, \mathbf{A}_{\text {mod }}$ and $\mathbf{A}_{d r o}$ (see Table 2). This simulation ignored the before versus after effect (due to habitat degradation under Hypothesis 1). The matrix summarizing wet years $\left(\mathbf{A}_{\text {wet1 }}\right)$ was based on means and average of all years that were identified as wet years for the period 1992 to 2005 (see Table 2). The matrix summarizing moderately dry years was based on means and averages of all years that were identified as dry years for the period 1992 to 2005 (see Table 2). We used matrix $\mathbf{A}_{d r o}$ to simulate drought years (Table 2). For Condition 5 we applied observed frequencies for each environmental state for the first 7 years of the study (i.e. 1992 to 1998 ; we refer to this environment as low frequency of moderate drying, LFMD). During this time period 1 drought year was observed (frequency: 1/7); no moderately dry years were observed (frequency: 0/7); and 6 wet year were observed (frequency: 6/7) (see 'Hydrological conditions').

- Condition 6: same as Condition 5, except that we used frequencies observed for the last 7 years, i.e. 1999 to 2005, high frequency of moderate drying (HFMD): 1 drought (1/7); 4 moderately dry years (4/7); and 2 wet years $(2 / 7)$.

Under Hypothesis 2 we make Prediction 2: $\lambda_{s}$ under Condition $5>\lambda_{s}$ under Condition 6 .

Hypothesis 3: increase in frequency of drying events and habitat conversion reduced $\lambda_{s}$ after 1998 (Objective 6). Hypothesis 3 assumes that both an increase in moderate drying events and habitat degradation have contributed to a decrease in $\lambda_{s}$ after 1998.

- Condition 7: we computed $\lambda_{s}$ by simulating an environment with 3 environmental states: $\mathbf{A}_{\text {wet2 }}, \mathbf{A}_{\text {mod }}$ and $\mathbf{A}_{\text {dro }}$. The matrix summarizing the wet years was estimated based on means and variances of parameters estimated prior to 1998. Ideally, we would also have computed matrices for $\mathbf{A}_{\text {mod }}$ and $\mathbf{A}_{\text {dro }}$ based on parameters estimated prior to 1998. Unfortunately, there were no data available for moderately dry years prior to 1998. Thus, matrices $\mathbf{A}_{\text {mod }}$ and $\mathbf{A}_{\text {dro }}$ were based on data collected after 1998, and were the same matrices used for Condition 5. For Condition 7 we applied the observed frequency for each environmental state for the first $7 \mathrm{yr}$ of the study (LFMD, see Condition 5).

- Condition 8: same as Condition 7, except we used frequencies observed for the last 7 years (HFMD: 1 drought, $1 / 7$; 4 moderately dry years, 4/7; and 2 wet years, 2/7).

- Condition 9: same as Condition 7, except the matrix summarizing the wet years was based on parameters estimated after 1998. We refer to this matrix as $\mathbf{A}_{\text {wet3 }}$ (Table 2). For Condition 9 we applied the observed frequency for each environmental state for the first 7 years of the study (LFMD, see Conditions 5 and 7).

- Condition 10: same as Condition 9, but we applied the observed frequency for each environmental state for the last 7 years of the study (HFMD, see Conditions 6 and 8).

Under Hypothesis 3 we make Prediction 3a: $\lambda_{s}$ under Condition $7>\lambda_{s}$ under Condition 8 ; and $\lambda_{s}$ under Condition $9>\lambda_{s}$ under Condition 10. We also make Prediction 3b: $\lambda_{s}$ under Condition $7>\lambda_{s}$ under Condition 9 ; and $\lambda_{s}$ under Condition $8>\lambda_{s}$ under Condition 10 .

All matrix analyses were conducted using MATLAB (Mathworks 2005).

\section{RESULTS}

\section{Objective 1}

When assuming $\hat{\beta}(t)=0.16, \lambda_{s}$ for the last 9 years was 0.937 (95\% CI $=0.933$ to 0.941$)$. When assuming $\hat{\beta}(t)=$ 0.16 to $0.35, \lambda_{s}$ for the last 9 years was $0.896(95 \% \mathrm{CI}=$ 0.893 to 0.899$)$. When assuming $\hat{\beta}(t)=0.70, \lambda_{s}$ for the last 9 years was $0.850(95 \% \mathrm{CI}=0.849$ to 0.851$)$.

\section{Objective 2}

The sensitivity analysis indicated that $\lambda_{1}$ was most sensitive to changes in adult survival and adult fertility (Fig. 1a). Sensitivity of $\lambda_{1}$ to changes in other vital rates $\left(F_{s}\right.$ and $\left.P_{s}\right)$ was considerably lower (Fig. 1a). Lower-level sensitivity analyses showed that sensitivity of $\lambda_{1}$ to changes in $m_{a}$ and $P_{j}$ were intermediate when compared to $F_{S}$ and $P_{a}$ (or $F_{a}$ ), whereas sensitivity of $\lambda_{1}$ to changes in $m_{s}$ were negligible (Fig. 1b). Elasticity analyses indicated that $\lambda_{1}$ was most sensitive to proportional changes in $P_{a}$ (Fig. 1c). Elasticity of $\lambda_{1}$ to changes in $F_{a}$ and $P_{s}$ were considerably lower $(<0.12)$. Elasticity of $\lambda_{1}$ to change in $F_{S}$ was almost 0 , and this was true independently of the detection probability assumed (Fig. 1c). Elasticity of $\lambda_{1}$ to changes in $m_{a}$ and $P_{j}$ were similar to the ones in $F_{a}$ and $P_{S}$, whereas elasticity of $\lambda_{1}$ to change in $m_{s}$ was almost 0 (Fig. 1d).

\section{Objective 3}

The $\lambda_{1}$ for matrix $\mathbf{A}_{\text {bef }}$ was 1.2 with $\hat{\beta}(t)=0.16,1.13$ with $\hat{\beta}(t)=0.16$ to 0.35 , and 0.95 with $\hat{\beta}(t)=0.70$. The $\lambda_{1}$ for matrix $\mathbf{A}_{a f t}$ was 0.95 with $\hat{\beta}(t)=0.16,0.92$ with $\hat{\beta}(t)=$ 0.16 to 0.35 , and 0.89 with $\hat{\beta}(t)=0.70$. 


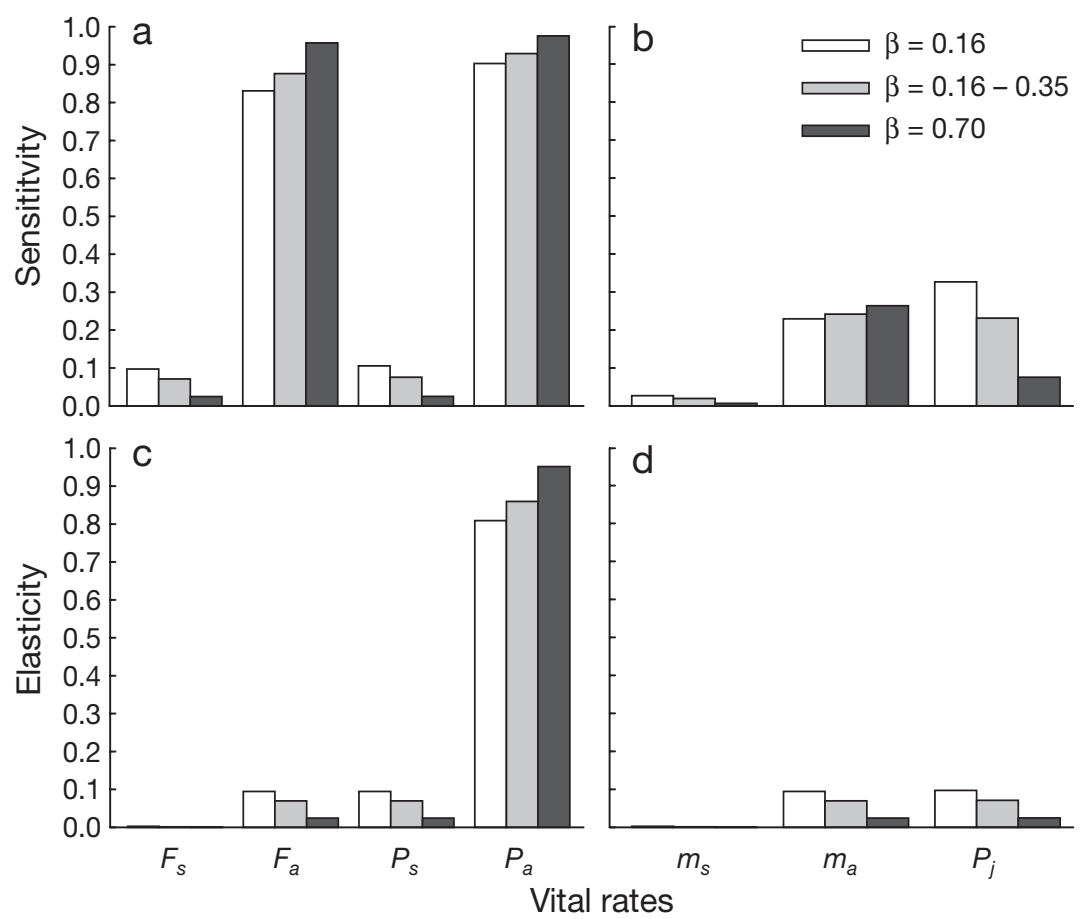

Fig. 1. Sensitivity $(a, b)$ and elasticity $(c, d)$ of $\lambda_{1}$ to changes in stage-specific vital rates. The sensitivity (b) and elasticity (d) of $\lambda_{1}$ to changes in $m_{s^{\prime}} m_{a \prime}$ and $P_{j}$ were obtained by conducting lower level sensitivity and elasticity analyses. Sensitivity and elasticity were estimated for 3 levels of detection probabilities of juveniles $\hat{\beta}(t)$ $=0.16, \hat{\beta}(t)=0.16$ to 0.35 , and $\hat{\beta}(t)=0.70$ ). See Table 2 for a list of abbreviations and symbols

frequency from 0.11 to 0.25 caused a large decrease in $\lambda_{s}$ (Fig. 3). There was evidence of a large reduction in $\lambda_{s}$ when comparing the before and after 1998 environments. $\lambda_{s}$ estimated from vital rates obtained prior to 1998 was substantially greater than $\lambda_{s}$ based on vital rates obtained after 1998. However, the magnitude of the difference decreased as detection probability increased (Fig. 3). The magnitude of the difference in $\lambda_{s}$ due to the change in conditions before and after 1998 was greater than the effect of an increase in drought frequency (from 0.11 to 0.25 ) when $\hat{\beta}(t)=$ 0.16 and $\hat{\beta}(t)=0.16$ to 0.35 were assumed. When $\hat{\beta}(t)=0.70$ was assumed, the reduction in $\lambda_{s}$ due to an increase in drought frequency was greater than the effect of the change in conditions before and after 1998 (Fig. 3). Fig. 3 shows that $\lambda_{s}$ under Condition $1>\lambda_{s}$ under Condition 3 ; and that $\lambda_{s}$ under Condition $2>\lambda_{s}$ under Condition 4, which provides some support for Prediction 1.

\section{Objective 5}

There was a large difference in $F_{a}$ between matrix $\mathbf{A}_{\text {bef }}$ and matrix $\mathbf{A}_{a f t}$ when detection probability was assumed to be 0.16 or varied from 0.16 to 0.35 (Fig. 2a). The reduction in $F_{a}$ was considerably lower when detection probability was assumed to be large $\hat{\beta}(t)=$ $0.70)$. When $\hat{\beta}(t)=0.16$ and $\hat{\beta}(t)=0.16$ to 0.35 was assumed, $F_{a}$ contributed the most to the reduction in $\lambda_{1}$ between $\mathbf{A}_{\text {bef }}$ and $\mathbf{A}_{\text {aft }}$ (contribution was $90 \%$ ), whereas $P_{a}, P_{s}$ and $F_{s}$ contributed less than $6 \%$ each (Fig. 2a). When $\hat{\beta}(t)=0.70$ was assumed, $F_{a}$ still contributed the most $(80 \%)$, but the contribution of $P_{a}$ was also greater $(18 \%)$. The decomposition of the contributions of $F_{a}$ and $F_{s}$ into $m_{a}$ and $m_{s}$ and $P_{j}$ showed that $m_{a}$ contributed more than any other parameters, and was closely followed by $P_{j}$ (Fig. $2 \mathrm{~b}$ ).

\section{Objective 4}

Under Conditions 1 to 4 there was an additive effect of drought frequency and the before versus after 1998 effect on $\lambda_{s}$ (i.e. habitat degradation under Hypothesis 1). The additive effect was due to the fact that we assumed the drought effect to be the same in the before and after 1998 environment. Increasing drought
Under Conditions 5 and $6, \lambda_{s}$ was greater when we simulated environmental states at the frequency observed during the first 7 year of our study (LFMD, Fig. 4). The magnitude of the difference was greater when detection probability was assumed to be low (Fig. 4). The reduction in $\lambda_{s}$ was due to the fact that the frequency of moderate drying events increased during the last 7 years (or alternatively, the frequency of wet years decreased). The frequency of droughts remained the same under these 2 environments, thus droughts did not contribute to the reduction in $\lambda_{s}$ when comparing these 2 environments. Fig. 4 shows that $\lambda_{s}$ under Condition $5>\lambda_{s}$ under Condition 6 , which provides some support for Prediction 2.

\section{Objective 6}

Under Conditions 7 to $10, \lambda_{\mathrm{s}}$ was greater when we simulated environmental states at the frequency observed for the first 7 years (LFMD, open symbols in Fig. 5) than for the last 7 years (HFMD, black symbols in Fig. 5). The magnitude of the difference decreased as $\hat{\beta}(t)$ increased. In addition, for a given frequency of 


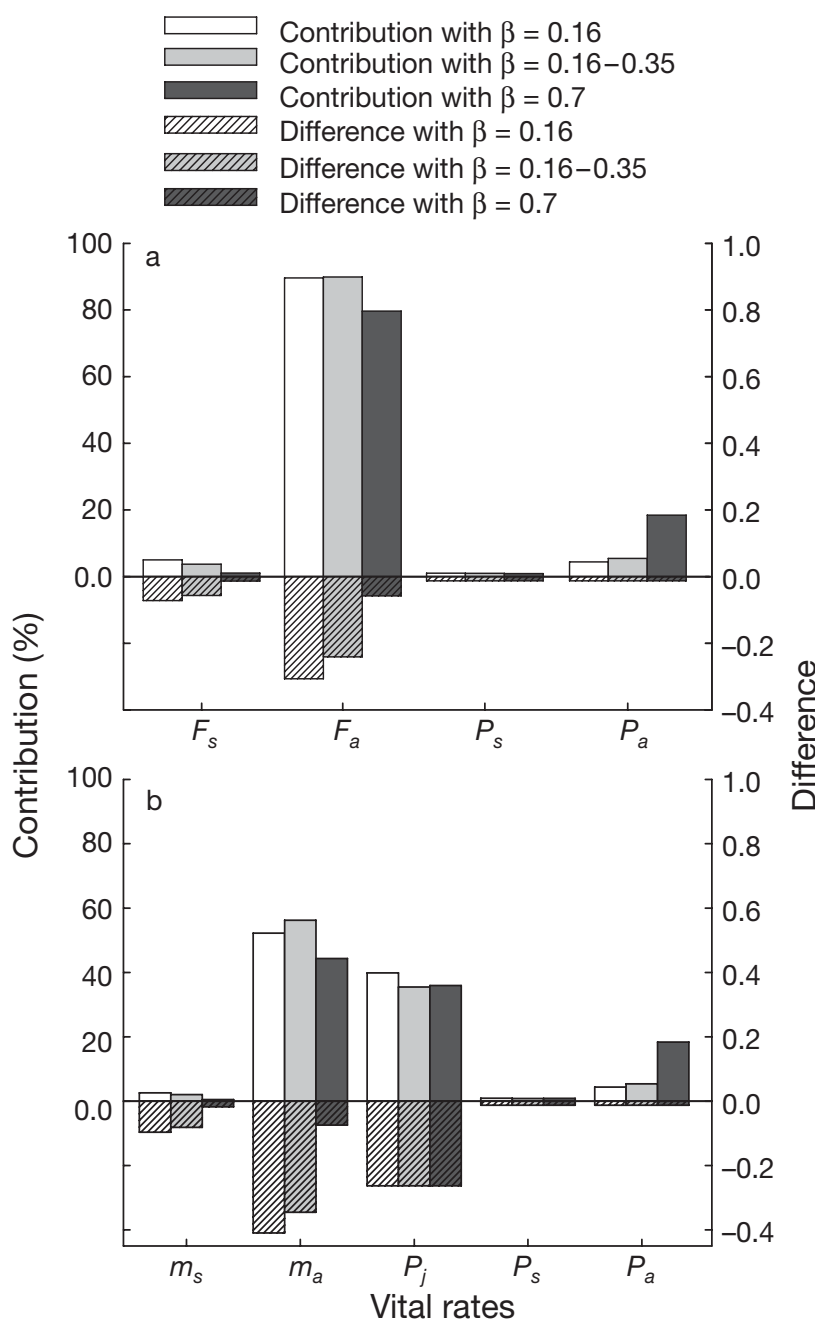

Fig. 2. (a) Difference in stage-specific vital rates between the matrix $\mathbf{A}_{\text {bef }}$ and matrix $\mathbf{A}_{\text {aft }}$ (negative bars, all differences were negative) and contributions (in \%) of those differences to the effect of changes in the environment on deterministic population growth rate $\lambda_{1}$ (positive bars) for upper-level parameters $F_{s}, F_{a}, P_{s}$ and $P_{a}$. (b) Same as (a), but where $F$ was decomposed into lower-level components $\left(m_{s}\right.$ and $P_{j}$ for $F_{s i}$ $m_{a}$, and $P_{j}$ for $F_{a}$ ). Differences and contribution were computed for 3 levels of detection probabilities of juveniles $\hat{\beta}(t)=$ $0.16, \hat{\beta}(t)=0.16-0.35$, and $\hat{\beta}(t)=0.70)$. See Table 2 for a list of abbreviations and symbols

moderate drying events, $\lambda_{\mathrm{s}}$ was greater when the simulations were based on parameters estimated with data collected before 1998 ('Before' in Fig. 5) than after 1998. The magnitude of the difference also decreased considerably as $\hat{\beta}(t)$ increased (Fig. 5). Fig. 5 shows that $\lambda_{s}$ under Condition $7>\lambda_{s}$ under Condition 8 ; and that $\lambda_{s}$ under Condition $9>\lambda_{s}$ under Condition 10, which provides support for Prediction 3a. Fig. 5 also shows that $\lambda_{s}$ under Condition $7>\lambda_{s}$ under Condition 9 ; and that $\lambda_{s}$ under Condition $8>\lambda_{s}$ under Condition 10, which provides support for Prediction $3 b$.

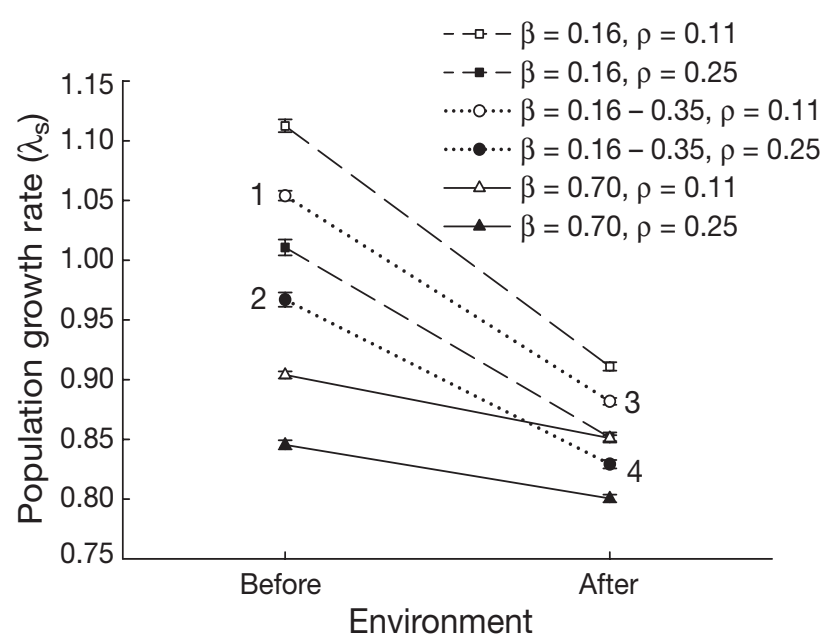

Fig. 3. Estimates of $\lambda_{s}$ for environmental conditions before and after 1998. For each environment (i.e. 'before' and 'after'), we simulated 2 frequencies of droughts: $\rho=0.25$ ( 1 drought every $4 \mathrm{yr}$ ) and $\rho=0.11$ (1 drought every $9 \mathrm{yr}$ ). Estimates of $\lambda_{s}$ were computed for 3 levels of detection probabilities of juveniles $\hat{\beta}(t)=0.16, \hat{\beta}(t)=0.16$ to 0.35 , and $\hat{\beta}(t)=0.70)$. Error bars correspond to $95 \%$ CI. Numbers next to circles indicate Conditions 1 to 4 for $\hat{\beta}(t)=0.16$ to 0.35 . See Table 2 for a list of abbreviations and symbols

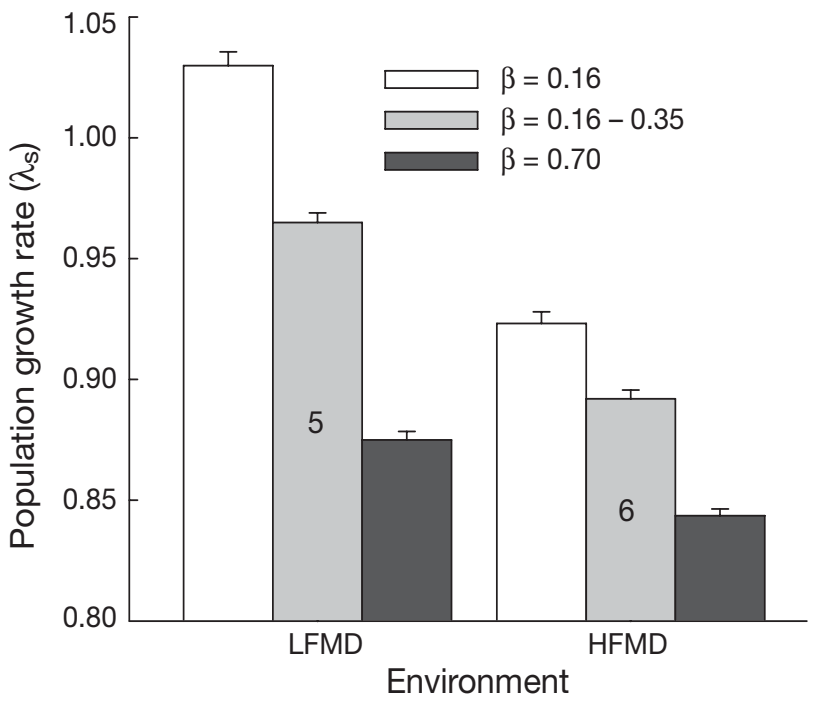

Fig. 4. Estimates of $\lambda_{s}$ assuming a low frequency of moderate drying events (LFMD) and a high frequency of moderate drying events (HFMD). LFMD corresponded to the frequency of wet, dry and drought years observed from 1992-1998. HFMD corresponded to the frequency of wet, dry and drought years observed from 1999-2005. Estimates of $\lambda_{s}$ were computed for 3 levels of detection probabilities of juveniles $\hat{\beta}(t)=0.16$, $\hat{\beta}(t)=0.16$ to 0.35 , and $\hat{\beta}(t)=0.70)$. Error bars correspond to $95 \%$ CI. Numbers inside bars indicate Conditions 5 and 6 for $\hat{\beta}(t)=0.16$ to 0.35 . See Table 2 for a list of abbreviations and symbols 


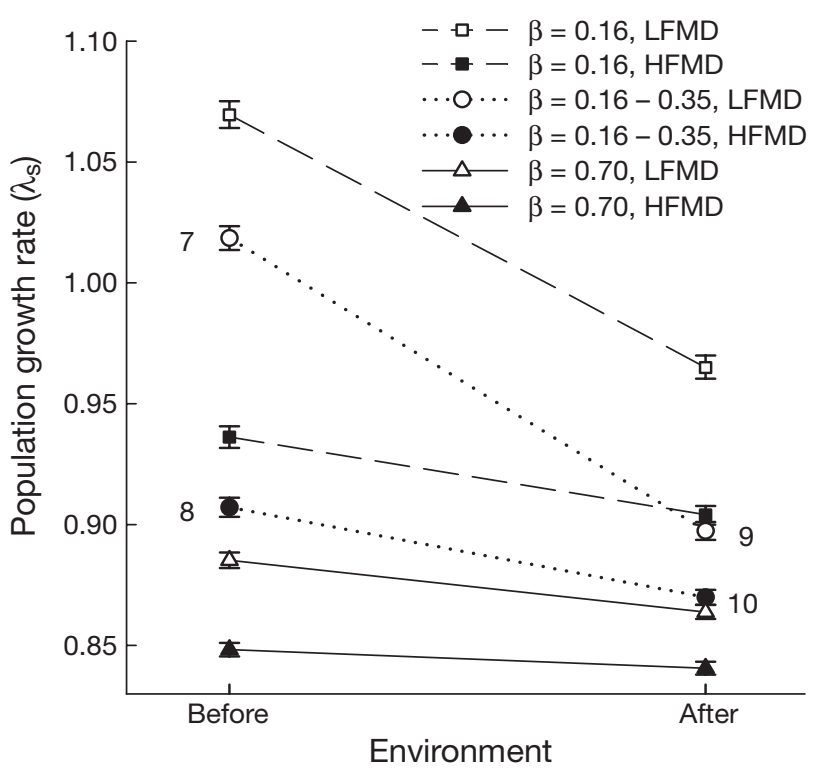

Fig. 5. Estimates of $\lambda_{s}$ for environmental conditions before and after 1998. For each environment (i.e. 'before' and 'after'), we simulated environments with 2 frequencies of wet, dry and droughts: LFMD (as in Fig. 4) and HFMD (also as in Fig. 4). Estimates of $\lambda_{s}$ were computed for 3 levels of detection probabilities of juveniles $(\hat{\beta}(t)=0.16, \hat{\beta}(t)=0.16$ to 0.35 , and $\hat{\beta}(t)=$ 0.70 ). Error bars correspond to $95 \%$ CI. Numbers next to circles indicate Conditions 7 to 10 for $\hat{\beta}(t)=0.16$ to 0.35 . See Table 2 for a list of abbreviations and symbol

\section{DISCUSSION}

\section{Population growth rate and key vital rates}

The stochastic population growth rate for the period 1997 to 2004 was low $\left(\lambda_{s}=0.90\right.$ for the most reasonable level of $\hat{\beta}(t)=0.16$ to 0.35 ). Thus, if the environmental conditions observed between 1997 and 2004 are representative of future conditions, kites will probably continue to decline in the future; these analyses addressed Objective 1. Caswell (2001) suggests that population projection models are particularly useful for evaluating the importance of demographic or environmental factors in influencing population dynamics. This latter notion motivated the sensitivity analyses, as well as the exploratory analyses discussed in the remaining part of our presentation.

We determined the sensitivity of $\lambda_{1}$ to absolute changes (i.e. sensitivities) and proportional changes (elasticities) in vital rates. These analyses addressed $\mathrm{Ob}-$ jective 2 . Elasticity of $\lambda_{1}$ to changes in adult survival was by far the greatest (Fig. 1c,d), which indicates that a proportional change in adult survival would cause the largest proportional change on $\lambda_{1}$. This pattern is typical among long-lived species (Stahl \& Oli 2006). Regarding sensitivity analyses, $\lambda_{1}$ was most sensitive to absolute changes in adult survival. Despite the greater elasticity of $\lambda_{1}$ to changes in adult survival, we found that adult fertility was still critical in influencing population growth rate (Fig. 2). $\lambda_{1}$ based on vital rates estimated for the period prior to 1998 was greater than $\lambda_{1}$ estimated from vital rates obtained for the period 1999 to 2005. The difference in $\lambda_{1}$ was substantial even after removing the effects of the 2001 drought. We performed a LTRE analysis that indicated the observed reduction in $\lambda_{1}$ for the 2 periods was largely due to a reduction in $F_{a}$ between these 2 periods (Fig. 2). We also conducted an LTRE analysis in which we decomposed fertilities into their lower level parameters (i.e. fecundity and $P_{j}$ ). This analysis showed that $m_{a}$ contributed more than any other parameters and was closely followed by $P_{j}$ (Fig. 2b). These findings addressed Objective 3. Thus, even though the dramatic reduction in $P_{a}$ during the 2001 drought contributed to a large decrease in population size (Martin et al. 2007b), other factors associated with a reduction in $F_{a}$ (primarily $m_{a}$ and to a lesser extent $P_{j}$ ) are responsible for the reduction in population growth. Next, we examined the 3 primary hypotheses explaining reduction in snail kite population growth during the most recent years.

\section{Hypothesis 1: habitat conversion caused a reduction of $\lambda_{s}$ after 1998 (Objective 4)}

Habitat conversion in the wetlands of south Florida, resulting from frequent and prolonged floods, has concerned some ecologists (e.g. Kitchens et al. 2002). Habitat conversion is believed to reduce apple snail densities (Darby et al. 2005) and could also reduce the availability of suitable nesting habitats for snail kites (Kitchens et al. 2002). Although other factors may have contributed to the decrease in population growth rate after 1998, the cumulative effect of flooding events on habitat conversion, especially in the WCAs, has been documented by several authors and should receive particular attention (Kitchens et al. 2002, Darby et al. 2005, Zweig \& Kitchens 2007).

As explained earlier, $\lambda_{1}$ was greater in the before than in the after1998 environment, even when removing the effects of the 2001 drought. The same pattern was observed for $\lambda_{s}$ (Fig. 3). The magnitude of the difference decreased when detection probability was assumed to be high. But in all instances the difference was substantial, indicating that some changes in the environment may have caused a decrease in population growth. This result supported Prediction 1. We examined the relative effects of drought frequency and the pre- versus post-1998 effect on $\lambda_{s}$. Thus, if we are ready to assume that the reduction in population growth was entirely due to habitat conversion, our stochastic analyses suggest that the effect of habitat conversion was greater (except when $\hat{\beta}(t)=0.70$ ) than a 
substantial increase in drought frequency (from 1 drought every 9 yr to 1 drought every 4 yr) (Fig. 3). This prospect is particularly alarming given the perceived slow dynamic of habitat conversion (Kitchens et al. 2002). Under this scenario, the positive effects of adequate habitat restoration plans on kite population growth would only be perceptible at the timescale of multiple years (i.e. multiple years may be needed to convert vegetation communities back to suitable kite habitats). However, as explained in the next section, it is unlikely that habitat conversion was solely responsible for the observed reduction in population growth.

\section{Hypothesis 2: increase in drying event frequency reduced $\lambda_{s}$ after 1998 (Objective 5)}

Under Hypothesis 2, we ignored the effect of habitat degradation, but still considered the effect of drought frequency. In addition to droughts with a large spatial and temporal extent (e.g. 2001 drought), we also considered drying events with a more moderate spatial and temporal extent. In fact, based on hydrological criteria developed by Bennetts (1998), these moderate drying events would not have been considered as a threat to kite persistence because it was believed kites could readily escape drying conditions by moving to less affected wetlands. Interestingly, we found that even if we ignored the effect of habitat degradation, an increase in moderate drying event frequency could reduce $\lambda_{s}$ substantially. We found that the increase in moderate drying events frequency observed during the last 7 years of our study could explain some of the observed variation in $\lambda_{s}$ between the before and after 1998 environments (Fig. 4). This result supported Prediction 2. There are several reasons that can explain the impact of moderate drying events on kite population growth. For instance, even though a proportion of adults may be able to move to wetlands less affected by a drying event, fledglings are less likely to be aware of refuge habitats and therefore are more likely to die during a drying event (Martin et al. 2006). The fact that $P_{a}$ is remarkably stable (except during extensive droughts, see Martin et al. 2006) is consistent with this hypothesis. Additionally, $P_{j}$ is strongly affected by drying events, even when they are moderate (Martin 2007).

\section{Hypothesis 3: increase in frequency of drying events and habitat conversion reduced $\lambda_{s}$ after 1998 (Objective 6)}

We believe that both habitat conversion and an increase in frequency of moderate drying events are highly relevant to our study system. Therefore, we examined $\lambda_{s}$ under Hypothesis 3, which considered both factors. Although we only had data to estimate vital rates during wet years in the pre- and post-1998 environment, we found evidence of a potential effect of both factors on $\lambda_{s}$ (Fig. 5). This result supports Predictions 3a and $3 \mathrm{~b}$. If we had used the 1992 data to construct the drought matrix for the pre-1998 environment, the differences in $\lambda_{s}$ due to the before versus after 1998 effect would have appeared to be even greater. It is in fact, possible that long-term habitat degradation has reduced the resistance of kite to droughts; however, given the uncertainty associated with 1992 (see Appendix 4) we preferred not to include 1992 into our analyses.

\section{Limits of the models}

The matrix population models used in our presentation ignored the effect of spatial structure, temporal correlation, density dependence, and genetic stochasticity. In Appendix 5, we provide a detailed discussion of these limits.

\section{Conservation implications}

Given the recent population decline and the critical state of the kites' reproductive parameters, the results of this study, although exploratory in nature, have important conservation implications. We focused primarily on hydrology (and did not explicitly address other potential causes of decline, such as predation, disease, etc.) because water availability has thus far been recognized as one of the most critical factor affecting kites population dynamics. Furthermore, the hypotheses that we examined in our study were the most relevant to current management efforts and were also among the hypotheses best supported by the existing literature. The relevance of our results to conservation is heightened because the snail kite has been selected as one of the key performance measures of the ongoing restoration activities associated with the Comprehensive Everglades Restoration Plan (RECOVER 2005). This federal-state effort includes numerous structural and management alternatives of the hydrology of the wetlands occupied by kites.

Previous modeling studies based on information at least 10 yr old (Beissinger 1995, Mooij et al. 2002, 2007) emphasized the importance of drought frequency on kite persistence. Our study, which was based on more recent data and on more robust estimators, was consistent with this finding. In addition, our study emphasized the potential importance of even moderate drying events in affecting kite persistence by suppressing 
reproduction and $P_{j}$. In the past, these moderate drying events were not considered critical (Bennetts 1998). However, under the current conditions, $F_{a}$ appears to be crucial and factors likely to have large effects on adult reproduction and $P_{j}$ should receive some attention. Based on our results, we suggest consideration of management regimes that reduce the frequency of moderate drying events during the spring-summer.

As discussed earlier, habitat conversion is also an important factor with the potential to have a large impact on kite population growth. As suggested by recent studies, the repeated flooding of the wetlands during the fall can result in habitat conversions and suppression of snail reproduction deemed detrimental to kites (Kitchens et al. 2002, Darby et al. 2005, Mooij et al. 2007, Zweig \& Kitchens 2007). Therefore, reducing flood duration and frequency should help restore vegetation communities favorable to kite habitats. This point emphasizes the importance of considering shortand long-term effects of disturbances when modeling population dynamics. Indeed, in the short term, flooding events may be beneficial to kites (Bennetts et al. 2002). However, the cumulative effects of flooding events over several years may induce shifts in vegetation communities that are detrimental to the population growth in the long term.

Assertions about the importance of droughts as an organizing force should also be carefully considered (i.e. droughts should not be systematically suppressed, see DeAngelis \& White 1994, Mooij et al. 2007). However, under the current system we foresee that an excess of droughts and moderate drying events could be a greater threat to kites than a lack of droughts. Indeed, water regulation schedules are generally constrained by growing demands for consumptive water use that contribute to increased drying events and intensities (Beissinger 1995, SFWMD 2007b). In addition, the United Nation's Intergovernmental Panel for Climate Change (IPCC 2007) predicts that global warming will lead to an increase in drought frequency and extent in the lower latitudes, including south Florida. Such a trend would create more frequent water shortages in wetlands occupied by kites during the spring-summer.

Furthermore, conducive water management in this critical area is challenging given its precarious placement, down-slope of Lake Okeechobee and up-slope of one of the critical habitats for the endangered Cape Sable seaside sparrow Ammodramus maritimus mirabilis in the Everglades National Park. The challenge is exacerbated by potential threats of increased tropical storm intensity in these areas associated with global warming (IPCC 2007). The concerns for accommodating outlets and storage of potential floodwater may currently be constraining regulation schedules for
Lake Okeechobee and the WCAs resulting in drier conditions in the spring-summer with storage excesses vented to WCA3A in the fall. Moving the fall excesses south is constrained by concerns for disrupting reproductive habitat for the Cape Sable seaside sparrow (US Army Corps of Engineers 2002).

Therefore, one challenge of restoration efforts in the WCA3A will be to identify water levels that allow the kite population to persist, while accommodating needs for other native species and without compromising socio-economic interests in central and south Florida. Adaptive management appears to be a natural framework to identify these water levels (see Williams et al. 2002, Nichols \& Williams 2006). The models and estimates presented in our study provide a starting point to initiate this process.

Acknowledgements. We thank J. Nichols, D. DeAngelis, P. Frederick, B. Bolker, J. Hostetler, A. Ozgul and F. Sergio for helpful suggestions. D. R. Bennetts and V. Dreitz designed the snail kite monitoring study. L. Wilcox helped with editing. Financial support was provided by the USFWS, the Florida Fish and Wildlife Conservation Commission, the St. John's River Water Management District and the USACO.

\section{LITERATURE CITED}

Beissinger SR (1995) Modelling extinction in periodic environments: Everglades water levels and Snail Kite population viability. Ecol Appl 5:618-631

Bennetts RE (1998) The demography and movements of Snail Kites in Florida. $\mathrm{PhD}$ thesis, University of Florida, Gainesville, FL

> Bennetts RE, Kitchens WM (2000) Factors influencing movement probabilities of a nomadic food specialist: proximate foraging benefits or ultimate gains from exploration? Oikos 91:459-467

Bennetts RE, Kitchens WM, DeAngelis DL (1998) Recovery of the Snail Kite in Florida: beyond a reductionist paradigm. Trans 63rd No Am Wildl Natur Resour Conf, p 486-501

Bennetts RE, Kitchens WM, Dreitz VJ (2002) Influence of an extreme high-water event on survival, reproduction, and distribution of snail kites in Florida. Wetlands 22:366-373

Bruna EM, Oli MK (2005) Elucidating the demographic consequences of habitat fragmentation for a tropical understory plant using life table response experiments. Ecology 86:1816-1824

Casagrandi R, Gatto M (2002) Habitat destruction, environmental catastrophes, and metapopulation extinction. Theor Popul Biol 61:127-140

Caswell H (2001) Matrix population models: construction, analysis, and interpretation. Sinauer Associates, Sunderland, MA

Darby PC, Karunaratne LB, Bennetts RE (2005) The influence of hydrology and associated habitat structure on spatial and temporal patterns of Apple Snail abundance and recruitment. University of West Florida, Pensacola, FL

DeAngelis DL, White PS (1994) Ecosystems as products of spatially and temporally varying driving forces, ecological processes and landscapes. Everglades. In: Ogden JC, Davis MS (eds) The ecosystem and its restoration. St. Lucie Press, Delray Beach, FL 
IPCC (2007) Climate change 2007 - The physical science basis. Working group I contribution to the fourth assessment report of the IPCC. Cambridge University Press, Cambridge

Kitchens WM, Bennetts RE, DeAngelis DL 2002. Linkages between the snail kite population and the wetland dynamics in a highly fragmented South Florida hydroscape. In: Porter JW, Porter KG (eds) The Everglades, Florida Bay, and coral reefs of the Florida Keys. CRC Press, Boca Raton, FL, p 183-203

Koons DN, Rotella JJ, Willey DW, Taper M and others (2006) Lesser Scaup population dynamics: what can be learned from available data? Avian Conservation and Ecology 1, 6. www.ace-eco.org/vol1/iss3/art6/, accessed June 1, 2008

Martin J (2007) Population ecology and conservation of the Snail Kite. PhD thesis, University of Florida, Gainsville http://etd.fcla.edu/UF/UFE0019653/martin_j.pdf, accessed March 25, 2008

Martin J, Nichols JD, Kitchens WM, Hines JE (2006) Multiscale patterns of movement in fragmented landscapes and consequences on demography of the snail kite in Florida. J Anim Ecol 75:527-539

Martin J, Kitchens WM, Hines JE (2007a) Natal location influences movement and survival of a spatially structured population of snail kites. Oecologia 153:291-301

Martin J, Kitchens WM, Hines JE (2007b) Importance of well designed monitoring programs for the conservation of endangered species: Case study of the Snail Kite. Conserv Biol 21:472-481

Mathworks (2005) MATLAB: the language of technical computing, using MATLAB. Version 7.1. The Mathworks, Natick, MA

Mooij WM, Bennetts RE, Kitchens WM, DeAngelis DL (2002) Exploring the effect of drought extent and interval on the Florida snail kite: interplay between spatial and temporal scales. Ecol Modell 149:25-39

Mooij WM, Martin J, Kitchens WM, DeAngelis DL (2007) Exploring the temporal effects of seasonal water availability on the Snail Kite of Florida. In: Bissonette JA, Storch I (eds) Temporal dimensions of landscape ecology. Springer, New York, p 155-173

Morris WF, Doak DF (2002) Quantitative conservation biology. Theory and practice of population viability analysis. Sinauer Associates, Sunderland, MA

Nichols JD, Williams BK (2006) Monitoring for conservation. Trends Ecol Evol 21:668-673
Oli MK, Slade NA, Dobson FS (2001) Effect of density reduction on Uinta ground squirrels: an analysis of life table response experiments. Ecology 82:1921-1929

RECOVER (2005) The RECOVER team's recommendations for interim targets for the Comprehensive Everglades Restoration Project, South Florida Water Management District and US Army Corps of Engineers, West Palm Beach, FL

Reeves GH, Benda LE, Burnett KM, Bisson PA, Sedell JR (1995) A disturbance-based ecosystem approach to maintaining and restoring freshwater habitats of ESU of Anadromous Salmonids in the Pacific Northwest. Am Fish Soc Symp 17:334-349

Smith SM, Gawlik DE, Rutchey R, Crozier GE, Gray S (2003) Assessing drought-related ecological risk in the Florida Everglades. J Environ Manag 68:355-366

South Florida Water Management District (2007a) South Florida Environmental Report, West Palm Beach, FL

South Florida Water Management District (2007b) Lower east coast water supply plan, 2005-2006 update, Planning Department, West Palm Beach, FL

Stahl JT, Oli MK (2006) Relative importance of avian life history variables to population growth rate. Ecol Model 198: 23-39

Takekawa JE, Beissinger SR (1989) Cyclic drought, dispersal and conservation of the Snail Kite in Florida: lessons in critical habitat. Conserv Biol 3:302-311

US Army Corps of Engineers (2002) Interim operational plan for protection of the Cape Sable seaside sparrow, final environmental impact statement, Jacksonville, FL

White GC, Burnham KP (1999) Program MARK: Survival rate estimation from both live and dead encounters. Bird Study 46(Suppl.):S120-S139

White PS, Pickett STA (1985) Natural disturbance and patch dynamics. In: Pickett STA, White PS (eds) The ecology of natural disturbance and patch dynamics. Academic Press, Orlando, FL

Williams BK, Nichols JD, Conroy MJ (2002) Analysis and management of animal populations. Academic Press, San Diego, CA

Zweig CL, Kitchens WM (2007) Habitat use of the endangered snail kite during Everglades restoration. Natl Conf Ecosystem Restor, Kansas City, MO. http://conference. ifas.ufl.edu/NCER2007/pdf/Abstract_BOOK.pdf, accessed January 8, 2007

Appendix 1. Details on how to derive $m_{a}$ and $m_{s}$ from estimates of population size

An estimate of the total number of juvenile females produced per adult female kites at time $t$ can be obtained from the product: $\hat{m}_{a}(t) \times \hat{N}_{a}(t)$. Similarly, an estimate of the total number of juvenile females produced by subadult female kites at time $t$ can be obtained from the product: $\hat{m}_{s}(t) \times$ $\hat{N}_{s}(t)$. Therefore an estimate of the total number of juvenile female $\hat{N}_{j}(t)$ (i.e. juvenile females produced by both adults and subadults) can be obtained from:

$$
\begin{aligned}
& \qquad \hat{N}_{j}(t)=\hat{m}_{a}(t) \times \hat{N}_{a}(t)+\hat{m}_{s}(t) \times \hat{N}_{s}(t) \\
& \text { Given that: } \hat{q}(t)=\frac{\hat{m}_{a}}{\hat{m}_{s}} \\
& \text { or equivalently: } \quad \hat{m}_{s}=\frac{\hat{m}_{a}}{\hat{q}(t)}
\end{aligned}
$$

by substituting $\hat{m}_{s}$ by $\frac{\hat{m}_{a}}{\hat{q}(t)}$ in Eq. (A1) we obtain:

$$
\hat{N}_{j}(t)=\hat{m}_{a}(t) \times \hat{N}_{a}(t)+\frac{\hat{m}_{a}}{\hat{q}(t)}(t) \times \hat{N}_{s}(t)
$$

which after some rearranging leads to:

$$
\hat{m}_{a}(t)=\frac{\hat{N}_{j}(t)}{\hat{N}_{a}(t)+\frac{\hat{N}_{s}(t)}{\hat{q}(t)}}
$$


Appendix 2. Estimation of $\mathrm{q}(t)$

Estimates of $\mathrm{q}(t)$ can be obtained based on estimates from Bennetts (1998):

$$
q(t)=\frac{m_{a}}{m_{s}}=\frac{S_{a} \times \delta_{a} \times \alpha_{a} \times Y_{a}}{S_{s} \times \delta_{s} \times \alpha_{s} \times Y_{s}}
$$

where $S_{i}$ corresponds to nest success (subscripts indicate the stage class to which the parameter pertains to: adults, ' $a$,' and subadults, ' $s)^{\prime}{ }_{i} \delta_{\mathrm{i}}$ is the probability of a bird attempting to breed; $\alpha_{i}$ is the number of breeding attempts per year; $Y_{i}$ is the number of young per successful nest; and the sex ratio is assumed to be 50:50 (see Beissinger 1995). Beissinger (1995) assumed no difference in nest success and number of young per successful nest; we use estimates of $S_{i}$ and $Y_{i}$ from Bennetts (1998) $\left(S_{a}=S_{s}=0.3 ; Y_{a}\right.$ $\left.=Y_{s}=1.9\right)$. Based on a radiotelemetry study, Bennetts (1998) estimated $\hat{\delta}_{\mathrm{a}}(1995)=1$ (i.e. $100 \%$ of the adult snail kites attempted to breed in 1995, which was a wet year), and $\hat{\delta}_{\mathrm{s}}(1995)=0.33$. Based on his radiotelemetry study, Bennetts estimated $\hat{\alpha}_{a}(1995)=1.4$, but did not get an estimate for $\alpha_{\mathrm{s}}$. Therefore we set $\alpha_{\mathrm{s}}=1$, based on Beissinger (1995), who noted most subadults nest later in the season. Thus, based on Bennetts estimates

$$
\hat{q}(1995)=\frac{0.3 \times 1 \times 1.4 \times 1.9}{0.3 \times 0.33 \times 1 \times 1.9}=4.24
$$

In contrast, based on Beissinger (1995), $\hat{\mathrm{q}}(t)=8$ during lag years, 8.8 during wet years, and 1 during drought (however, this latter estimate was based on less reliable data). We used $\hat{\mathrm{q}}(t)$ based on Bennetts (1998) estimates because these estimates were more recent. Varying $\mathrm{q}(t)$ from 4 to 8.8 had little effect on population growth rates and other relevant measures.

Appendix 3. Detection probability of juveniles

Estimates of detection probability of juveniles $\hat{\beta}(t)$ were available only for 2004 and 2005 (Martin et al. 2007b). In contrast, estimates of detection of adults were available for the period 1997 to 2005. Martin et al. (2007b) found that detection for the adults increased linearly over time between 1997 and 2005. They suggest that this increase in detection was the result of an increase in search effort. Thus, we fitted a linear regression to their data (Table 2, MC data); the dependent variable was detection of adults $\hat{\beta}_{\mathrm{a}}(t)$ and the independent variable was 'year' $(t)$. We found a significant relationship $(F=24.63, \mathrm{df}=1$ and $6, \mathrm{p}=$ $0.0025, R^{2}=0.80$ ):

$$
\beta_{\mathrm{a}}(t)=-38.1158+0.0192 \times t
$$

We adjusted this equation for detection of juveniles so that detection in 2005 would equal 0.35, which was the estimate obtained by Martin et al. (2007b) for the year 2005. We computed annual detection of juveniles using the latter equation, except for 2004, for which an estimate of detection was available $(\hat{\beta}(t)$ in 2004 was 0.16$)$. Martin et al. (2007b) emphasized that the estimate for 2004 was unusually low, probably because of logistical problems that occurred in 2004. Thus, detection probabilites based on the latter equation varied between 0.16 and 0.35 (i.e. $\hat{\beta}(t)=0.16$ to 0.35$)$. Martin et al. (2007b) cautioned about these estimates of detection for juveniles because of scattered data. Therefore, in order to assess the robustness of our analyses we also repeated our analyses based on a conservative overestimate of juvenile detection probability, $\hat{\beta}(t)=0.70$, which was basically twice the estimate obtained in 2005. When detection of juveniles was considered to be 0.70 , we assumed a constant detection for all years. We also conducted our analyses assuming a constant detection probability of $\hat{\beta}(t)=0.16$. It is probably safe to assume that the average detection of juveniles during our study period was between 0.16 and 0.70 . Therefore, to account for the uncertainty associated with estimates of detection probabilities we repeated all our analyses for 3 levels of detection probabilities of juveniles $(\hat{\beta}(t)=0.16$, $\hat{\beta}(t)=0.16$ to 0.35 , and $\hat{\beta}(t)=0.70)$. 
Appendix 4. Rationales for the years selected to construct matrices $\mathbf{A}_{a f t}$ and $\mathbf{A}_{d r o}$

Rationales for the years that were selected to construct some of the matrices used in this analysis are presented in 'Materials and methods,' and here we provide additional information for the following 2 matrices: $\mathbf{A}_{a f t}$ and $\mathbf{A}_{d r o}$.

Matrix $\mathbf{A}_{\text {aft }}$ summarized vital rates estimated after 1998. Estimates of $m_{a}$ and $m_{s}$ included years: 1999, 2000 and, 2002 to 2005. Estimates of $P_{a}, P_{s}$, and $P_{j}$ included years: 1999 and 2002-2004. We excluded vital rates affected by the 2001 drought from this matrix. The 2001 drought affected $P_{j}$ and $P_{a}$ during the time intervals 2000-2001 and 2001-2002. Therefore, we excluded survival estimates $P_{a}$, $P_{S \prime}$ and $P_{j}$ at time 2000 (i.e. 2000-2001) and time 2001 (i.e. 2001-2002) in order to estimate $P_{a}, P_{s}$ and $P_{j}$ for matrix $\mathbf{A}_{\text {aft }}$.

Matrix $\mathbf{A}_{d r o}$. summarized vital rates estimated during the 2001 drought. Estimates of $m_{a r}$ and $m_{s}$ included 2001 because the drought affected fecundity that year. Estimates of $P_{a} P_{s}$ also included 2001. Estimates of $P_{j}$ included 2000 to 2001 . The 2001 drought affected juvenile and adult survival at time 2000 (i.e. 2000 to 2001) and time 2001 (2001 to 2002).

The effect of the 2001 drought on $P_{a}$ during the interval 2000 to 2001 was moderate because the effect of the drought started at the beginning of the 2001 sampling occasion. In contrast, the effect of the drought on $P_{a}$ was strongest during the interval 2001-2002 (time 2001). Survival estimates of adults were most representative of the drought effect during the interval 2001-2002. We could have used the same time interval for the estimates of $P_{j}$ during the 2001 drought; however, no juveniles were pro- duced out of the WCAs in 2001 (all kites were produced in the Kissimmee Chain of Lakes in 2001). Contrarily, most kites were produced out of the WCAs in 2000. Therefore, by averaging survival estimates for these 2 time periods we obtained an estimate that was more representative of the entire population (rather than just for the birds from the Kissimmee Chain of Lakes). We note that because the estimates of $P_{j}$ at time 2000 and time 2001 were very similar, using the estimates for 2001 only (instead of the average estimates for time 2000 and 2001) would have had negligible effects on our results.

Although the hierarchical clustering analysis conducted by Martin (2007) identified 1992 and 2001 as drought years, the $\mathbf{A}_{\text {dro }}$ matrix only included estimates for the 2001 drought. Next we provide a rationale for this choice. The effect of the 1992 drying event on $P_{j}, P_{s}, P_{a}$, and reproduction was considerably less than during the 2001 drought (Martin 2007, p 138). There are 3 main explanations for this observation. First, kite habitat may not have been as affected by habitat conversion as in 2001, and therefore for a similar drying event the resistance of kites to drought may have decreased in 2001 due to habitat conversion. Second, the 1992 drying event was less intense, was shorter and had a smaller spatial extent than the 2001 drought (Martin 2007, p 167). Finally, there may have been more suitable habitat outside the WCAs in 1992 than in 2001. Because of all the uncertainties associated with the 1992 drying event the matrix that summarized drought conditions was based on vital rates affected by the 2001 drought.

Appendix 5. Limits of the models

First, because estimates of detection of juveniles were only available for 2004 and 2005, we had to find ways to account for detection for the period 1997 to 2003 (see 'Materials and methods'). Although detection of juveniles was not directly estimated from 1997 to 2003, it is probably safe to assume that the 'true' values of $\hat{\beta}(t)$ were in fact between 0.16 and 0.70 . Therefore, by including analyses that assumed 3 levels of detection probabilities of juveniles $(\hat{\beta}(t)=0.16, \hat{\beta}(t)=0.16$ to 0.35$)$, we evaluated the robustness of our analyses to large changes in $\hat{\beta}(t)$. An alternative to compute fecundity rates would have been to derive this rate from $\alpha_{i}, S_{i}, \delta_{i}, Y_{i}$, and the sex ratio (assumed to be 50:50) (Bennetts 1998). The reason we did not use this approach is that we currently do not have good estimates of $\alpha_{\mathrm{i}}$ and $\delta_{\mathrm{i}}$ under varying environmental conditions.

Second, we ignored density dependence because at this point there is no evidence of density dependence in this population of snail kites (i.e. correlating vital rates with population size does not indicate any relation reflecting density dependence, J. Martin unpubl. data). As pointed out by Beissinger (1995) the setting of an upper boundary would have been arbitrary and, therefore, should be avoided. Ignoring density dependence in our models allowed population size to grow to levels unlikely to occur in Florida (Beissinger 1995). Thus, we expect estimates of population growth to be positively biased. Another shortcoming of our study is that we ignored temporal correlation. For instance, some ecologists have hypothesized that foraging conditions for kites should be lower than average 1 yr after a drought (Beissinger 1995). This is certainly a reasonable assumption. We did not include this effect for 2 reasons. First, fecundity and survival were lower than average for the year after the 2001 drought, but this could be because 2002 was a moderately dry year. In fact, if we compare vital rates of 2002 with vital rates after 1998, the rates are not lower than average. So including a lag effect based on our data would not have addressed concerns about lag effect. Thus, rather than imposing arbitrary reduction in vital rates we preferred to ignore this effect. If lag effects have major influences on kites, our estimates of stochastic population growth rates would be overestimated.

Another limitation of our approach is that we did not account for the spatial structure of the kite population. Taking spatial structure into consideration would be a useful next step. However, Morris \& Doak (2002) provide a useful discussion about the risks associated with detailed models (e.g. parameters less well supported by the data). In any case, we think that our approach is a useful one because it is based on robust parameter estimates (e.g. survival rates were based on Cormack-Jolly-Seber model) and provides a good starting point for further modeling efforts. Moreover, even though the snail kite population is spatially structured, there is enough movement among habitats for the population to be considered a single population, as opposed to a strict metapopulation (Bennetts \& Kitchens 2000, Martin et al. 2006). Finally, our work focused on a limited number of factors. Other disturbances or catastrophes, such as fire or diseases, etc., were ignored. 